\title{
GCU
}

Glasgow Caledonian

University

University for the Common Good

\section{A "Local Climate Zone" based approach to urban planning in Colombo, Sri Lanka}

Perera, N. G. R.; Emmanuel, R.

Published in:

Urban Climate

DOI:

10.1016/j.uclim.2016.11.006

Publication date:

2018

Document Version

Author accepted manuscript

Link to publication in ResearchOnline

Citation for published version (Harvard):

Perera, NGR \& Emmanuel, R 2018, 'A "Local Climate Zone" based approach to urban planning in Colombo, Sri Lanka', Urban Climate, vol. 23, pp. 188-203. https://doi.org/10.1016/j.uclim.2016.11.006

\section{General rights}

Copyright and moral rights for the publications made accessible in the public portal are retained by the authors and/or other copyright owners and it is a condition of accessing publications that users recognise and abide by the legal requirements associated with these rights.

Take down policy

If you believe that this document breaches copyright please view our takedown policy at https://edshare.gcu.ac.uk/id/eprint/5179 for details of how to contact us. 


\title{
A "Local Climate Zone" based approach to urban planning in Colombo, Sri Lanka
}

\author{
N G R Perera ${ }^{1}$, R Emmanuel ${ }^{2}$ \\ ${ }^{1}$ Department of Architecture, University of Moratuwa, Sri Lanka, nareinperera@gmail.com \\ ${ }^{2}$ School of Engineering and Built Environment, Glasgow Caledonian University, UK \\ Rohinton.Emmanuel@gcu.ac.uk
}

\begin{abstract}
Integrating climate-sensitive design with the local planning process is fundamental to managing the warming trend in the growing high-density tropical cities. However, the current planning regime is yet to address the challenges posed by local, regional and global warming. An in-depth understanding of the interaction between the physical form and the climatic context is beginning to emerge but, data needs and methods of analysis remain problematic at present to translate this into practical planning applications. In this paper, we showcase a simpler method of contextual analysis using the Local Climate Zone (LCZ) system and draw lessons for climate-sensitive planning in warm humid Colombo, Sri Lanka and other data-poor developing cities.
\end{abstract}

Keywords: Warm Humid Tropics; Local Climate Zone; Urban Planning; Climate sensitive design

\section{Citation:}

Perera NGR, Emmanuel R. 2016. A "Local Climate Zone" based approach to urban planning in Colombo, Sri Lanka, Urban Climate, http://dx.doi.org/10.1016/j.uclim.2016.11.006 


\section{Highlights}

- A simpler method of contextual analysis using the Local Climate Zone (LCZ) system is presented

- The LCZ classification system has significant advantages for climate sensitive urban planning even in data poor regions

- LCZ classification could help identify hot spots where further planning interventions may be needed

- Simplification of the LCZ classification/sub-classification may be needed in data poor regions to enhance applicability 


\section{Introduction}

It is now well agreed that adapting to climate change is better addressed at the city scale (Mills et al., 2010; Mills, 2007; Grimmond et al., 2010; Georgescu et al., 2014). Given the rapid growth in urbanisation, the associated serious degradation of environmental conditions and the lower cost of adaptive action, tropical cities are ripe for such action. Yet, knowledge of climate change, and especially the local urban climate change in tropical cities is weak. Not only are there fewer studies on tropical urban climate, the available work is biased towards descriptive studies (Roth, 2007). Application of climate knowledge in urban planning in the tropics remains rare $(\mathrm{Ng}, 2016)$.

One of the key difficulties in applying urban climate knowledge to planning decision making in the tropics is the lack of data, both in terms of significant land use land cover elements as well as their effects on local climate. Furthermore, the results of urban climatology are not communicated in a way that is meaningful or understood by city planners (Oke, 2006). A system that could bridge both these difficulties is the recently proposed Local Climate Zone (LCZ) approach - a classification system that attempts to define urban areas into 10 built and 7 land cover types of 'uniform regions of surface-air temperature distribution' (Stewart and Oke, 2012, Stewart et al., 2014). It is increasingly being applied to tropical contexts (Villadiego and Velay-dabat, 2014; Siu and Hart, 2013; Peng and Jim, 2013; Thomas et al., 2014; Puliafito et al., 2013, etc.) as well as elsewhere (Emmanuel and Loconsole, 2015; Middel et al., 2014; Unger et al., 2014; Alexander and Mills, 2014; Leconte et al., 2015; Müller et al., 2013).

In this paper we present our experience in applying an LCZ-based approach to classifying a tropical city (Colombo, Sri Lanka) and the implications of such an approach to climate-sensitive urban planning in a data-poor region. Thoughts on simplification of the LCZ approach to suit the local realities and ways in which monitoring of urban development could be facilitated by such an approach are presented. The rest of the paper is organised as follows. Section 2 summarises recent urban climate studies and the planning context of Colombo. Section 3 outlines the method of classification and sources of data while the experience of classification, mapping projected land cover changes in the city and difficulties encountered in a data-poor region are presented in Section 4. Thoughts on the simplification of the process and integrating it with the planning regime are presented in Section 5 while Section 6 explores the way forward.

\section{Background}

\subsection{Local context}

Colombo, Sri Lanka's largest city $\left(6^{\circ} 55^{\prime} \mathrm{N}, 79^{\circ} 51^{\prime} \mathrm{E}\right)$ has a warm, humid climate (Köppen-Geiger classification = Af - Tropical Rainforest Climate), with no seasonal differences in temperature or moistness and year-round rainfall. It is predominantly residential: $42 \%$ of the land use within the city limits is residential with commercial and other business uses occupying $3.5 \%$ and $4.5 \%$ respectively (JICA, 2014)(Fig. 1). This results in a continuous but low-rise built form in many areas except in the central business district. The Indian Ocean on the West and wetlands on the East of the city have led to a North-South elongated urban form, with the main traffic arteries in this direction surrounded by mid-rise development that is currently being transformed into high-rise (over 10 storeys). 


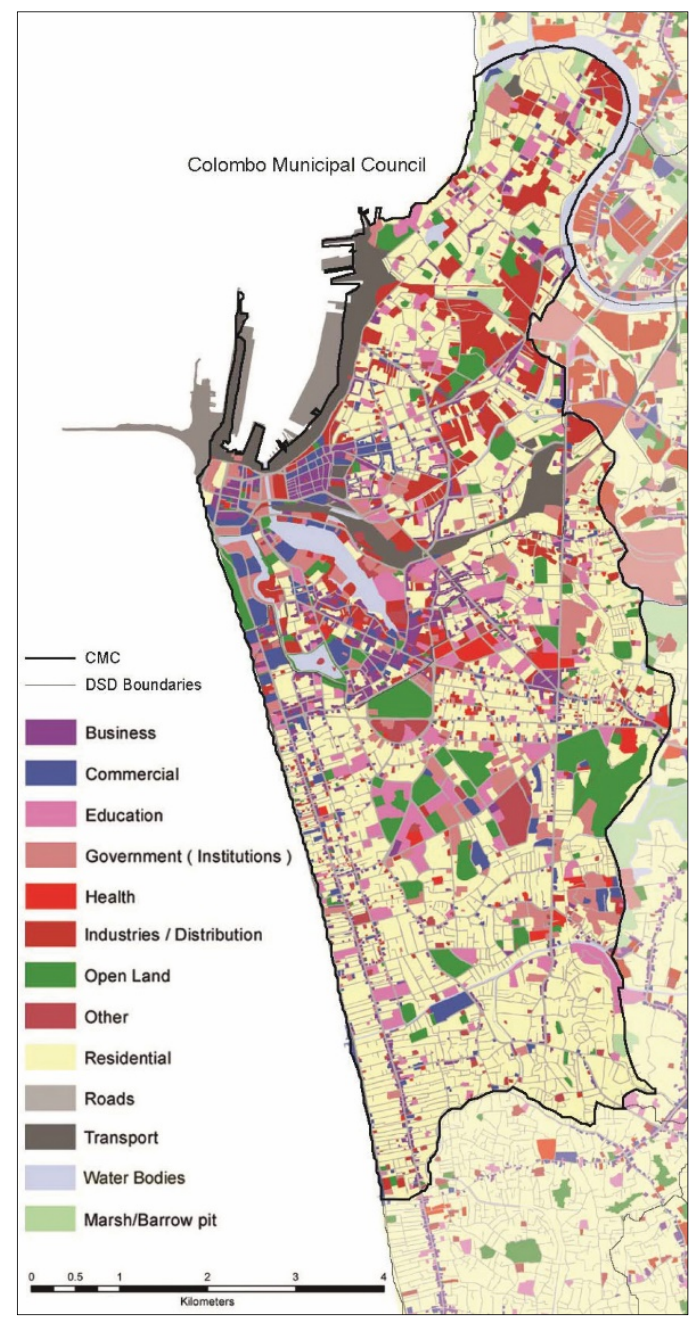

Figure 1: Land use map of Colombo, 2013

Source: JICA, 2014

Colombo is fast changing in terms of land use patterns, building morphology and population density. Although population growth in the country has largely abated in Sri Lanka (from a high of $2.8 \%$ per annum in 1950 s to $0.7 \%$ per annum in 2012 ), urban population in Colombo has grown by $38.6 \%$ in 1981-2012. Colombo's population density has increased by 32\% during the same period (Dept. of Census and Statistics, 2012).

Urban development in the city of Colombo is managed by the Urban Development Authority (UDA), whose zoning and building regulations - City of Colombo Development Plan (Amendment) - 2008 (http://colombo.mc.gov.lk/downloads/ccdp-2008.pdf) prepared under the Urban Development Authority Law No. 41 of 1978 (Gazette of Democratic Socialist Republic of Sri Lanka Extraordinary No $1535 / 4$ of $06^{\text {th }}$ February, 2008) form the basis of development control, using four main planning tools:

Zoning Plan and Planning regulations - primarily based on land use, building height and functions

Density Regulations - controls via building height, Built Surface Fraction (BSF) and Floor Area Ratio (FAR) 
Building Regulations - focus on space around buildings with plots, with some controls on plot size, street width, street frontage and maximum permissible FAR

Development Guide Plans (DGP) - special focus areas in the city that have specific restrictions on the local morphology in terms of the above three.

Colombo's development plan has undergone several revisions, with the latest plan ("Urban Development Authority Projected Zoning Plan for 2020" -

http://www.uda.gov.lk/index.php?option=com content\&view=article\&id=25\&ltemid=149\&lang=en) placing greater emphasis on a FAR-based strategy. The current plan also saw a redefinition of the land use zoning together with the permissible uses within the zones. It is deemed the newer zoning allows for greater flexibility, therefore brings a certain heterogeneity to the built fabric, although this in turn is likely to free land for intense development, especially in the port related activity zone.

(Perera, 2015)

\subsection{Urban climate in Colombo}

Colombo's urban climate is well documented (Emmanuel 2005; Emmanuel and Johansson, 2006; Johansson and Emmanuel, 2006; Emmanuel et al., 2007). These point to the advantages of deeper canyons on daytime thermal comfort but pollution dispersion and ventilation penalties, especially in residential areas could be significant. Horizontal shading by way of trees, arcades and covered walkways, with wind corridors perpendicular to the sea and a mixed urban morphology to enhance turbulence are also suggested.

Given the rapid rise in urban population and population density in Colombo, Perera (2015) explored the likely local warming due to urban morphological changes in the city (Table 1).

Table 1: Likely local warming due to urban fabric changes in Colombo

Source: Perera, 2015

\begin{tabular}{llc}
\hline Zone \# & \multicolumn{1}{c}{ LOCAL CLIMATE ZONE } & $\begin{array}{c}\text { Urban / Rural } \\
\text { Temperature } \\
\text { Difference }\left({ }^{\circ} \mathbf{C}\right)\end{array}$ \\
\hline $\mathbf{1}$ & compact high-rise & 4.40 \\
$\mathbf{2}$ & compact mid-rise & 3.96 \\
$\mathbf{3}$ & compact low-rise & 3.19 \\
$\mathbf{4}$ & open high-rise & 4.35 \\
$\mathbf{5}$ & open mid-rise & 3.71 \\
$\mathbf{6}$ & open low-rise & 1.87 \\
$\mathbf{7}$ & lightweight low-rise & 0.31 \\
$\mathbf{8}$ & large low-rise & 1.10 \\
$\mathbf{9}$ & sparsely built & - \\
$\mathbf{1 0}$ & heavy industry & - \\
$\mathbf{A}$ & dense trees & -0.12 \\
$\mathbf{B}$ & scattered trees & -0.09 \\
$\mathbf{C}$ & bush, scrub & - \\
\hline D & low plants & -0.64 \\
E & bare rock or paved & 1.04 \\
F & bare soil or sand & -0.90 \\
G & Water & 0.62 \\
\hline
\end{tabular}

Table 1 shows the intra-urban temperature differences to be in the range of $-0.9^{\circ} \mathrm{C}$ to $4.40^{\circ} \mathrm{C}$. Although large areas of Colombo remain low-rise, several blocks along major traffic arteries are 
witnessing an infusion of mid-rise and high-rise blocks (typically, a change in LCZ class 7 to 3), which appears to lead to greater UHI intensity. Large or open low-rise classes (LCZ8 and 6) in combination with soft land cover (LCZ A through F) and materiality aspects of the urban fabric can greatly modulate the local warming intensity (Perera, 2016).

\section{Method}

Given the rapidly increasing urban population density and significant changes to urban morphology in Colombo, the aim of this paper is to classify the city into local climate zones (LCZ) and explore the implications of such an approach to climate-sensitive urban planning, policy making and compliance monitoring in a data-poor region. An LCZ-based approach offers flexibility to local areas (neighbourhoods and urban blocks within cities) in terms of key variables that impinge on local climate with minimal data input while a more 'traditional' approach (such as the "urban climatic mapping" [e.g., "UC maps" and "climatopes"; see Ng and Ren, 2015; Ren et al., 2011]) is more data intensive but offers a city-level overview of climate needs and resources. LCZ classification protocols are detailed in Stewart and Oke (2012) and Stewart et al., (2014). Remotely sensed data were used for a supervised classification of LCZs, following the protocols established by the World Urban Database and Access Portal Tools (WUDAPT) workflow (Ching, 2013; See et al., 2015; Bechtel et al., 2015; Brouse et al., 2016).

The LCZ classification scheme recognises 17 standard classes (10 built and 7 land cover). Stewart and Oke (2012) specify a three step process: collect site metadata, define the thermal source area and select the local climate zone. The main source for information was a detailed map of Colombo (in Autodesk AutoCAD format generated from geographic information system (GIS) data). This includes information on urban blocks, building footprint, roads, water bodies and land contours (see Figure 2 for a sample area of this map for Colombo). Ground verification and modification of the block boundaries was done using field surveys and Google Earth. Each urban block was mapped individually, matching similar and adjacent blocks in situations where similarities were obvious. Indepth knowledge of the context and the availability of an accurate digital base map of the city hastened the process. Table 2 shows the detail methods adopted to determine climatically significant metadata for the LCZ classification.

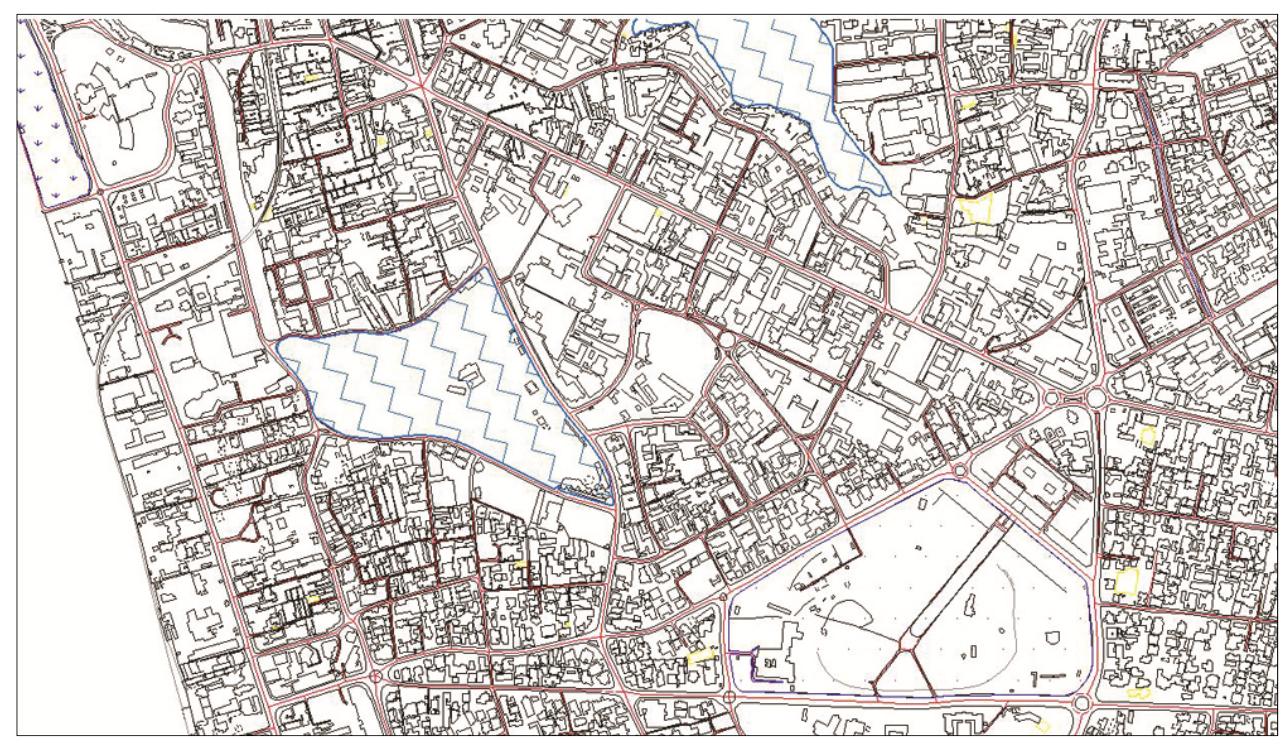

Figure 2: Sample detailed map of Colombo 
Table 2: Data collection methods

\begin{tabular}{ll}
\hline Property & Method adopted \\
\hline Sky View Factor (SVF) & Fish-eye lens photographs, field surveys \\
\hline Aspect ratio (H/W) & Detailed maps, field surveys, Google Earth \\
Building Surface fraction (BSF) & Detailed maps, Google Earth, Field surveys \\
\hline Impervious Surface fraction (ISF) & Detailed maps, Google Earth, Field surveys \\
Pervious surface fraction (PSF) & Detailed maps, Google Earth, Field surveys \\
Height of Roughness Elements (HRE) & Detailed maps, Field surveys, Google Earth \\
\hline Terrain Roughness class & LCZ data sheets (Stewart and Oke, 2012) \\
Surface admittance & LCZ data sheets \\
\hline Albedo & LCZ data sheets and field survey observations \\
\hline Anthropogenic heat flux & LCZ data sheets \\
\hline
\end{tabular}

The objective of Step 2 of the process (definition of thermal source area) is to understand the city in terms of morphology and its influence on the local climate. We used the WUDAPT protocol, using freely available data and software for this step. Urban block data (an example of which is shown in Figure 2) was used as the primary element for creating 'training sites' under the WUDAPT workflow.

Finally, the relevant Local Climate Zone for each block was determined by correlating the observed data with that of the selection guideline developed by Stewart and Oke $(2012,2014)$. Given the organic growth of Colombo over the years, many of the LCZ classes needed to be sub-classified. The sub-classification depended on how the site properties differ from the nearest equivalent in the data set. As defined by Stewart and Oke (2012) consideration was given to building types, special building properties, land cover types and to a lesser extent, seasonal land cover properties.

\section{Results and discussions}

\subsection{Initial classification}

Figure 3 shows the initial LCZ classification of Colombo. It is shown that, although Colombo is dominated by low-rise residential and mixed-use zones, these urban blocks are seeing an infusion of mid-rise and high-rise blocks. LCZ3 - compact low-rise (48.1\%) is the predominant classification in the city. This corresponds to the extensive residential land use identified in Figure 1. Areas classified as LCZ2 - compact mid-rise (8.9\%) and LCZ8 - large low-rise (23.7\%) are also significant. High fraction of LCZ8 is due to the presence of institutional landuse interlaced with those of other uses - particularly schools. LCZ1 - compact high-rise (0.3\%) and LCZ4 - open high-rise (1\%) form a very small fraction of Colombo's built fabric. A small fraction of Colombo comes under the category of LCZ7 - Lightweight low-rise (4.9\%). In this perspective, Colombo - although the densest city in Sri Lanka - still has the potential to be developed with climate as an important concern, considering the abundance of LCZ classes that have low climatic impact. These low impact classes as detailed in Table 1 above mainly include LCZ3 and LCZ8 but also LCZ5 and LCZ6.

The LCZ classification of the city was a relatively rapid process that took approximately 50 manhours. The process of urban block selection and metadata collection was conducted simultaneously, owing to the fact that the observational data collection method, mainly based on field surveys, using Google earth imagery and relevant detailed maps was common to both steps. Given the current planning controls in Colombo (see discussions under Section 2.1) it is also possible to categorise future development to create a 'proposed' LCZ map of the city (see Figure 4). The incorporation of geometric, surface cover, thermal, radiative, and metabolic properties embedded in local climate zones, highlight critical areas of the city. 


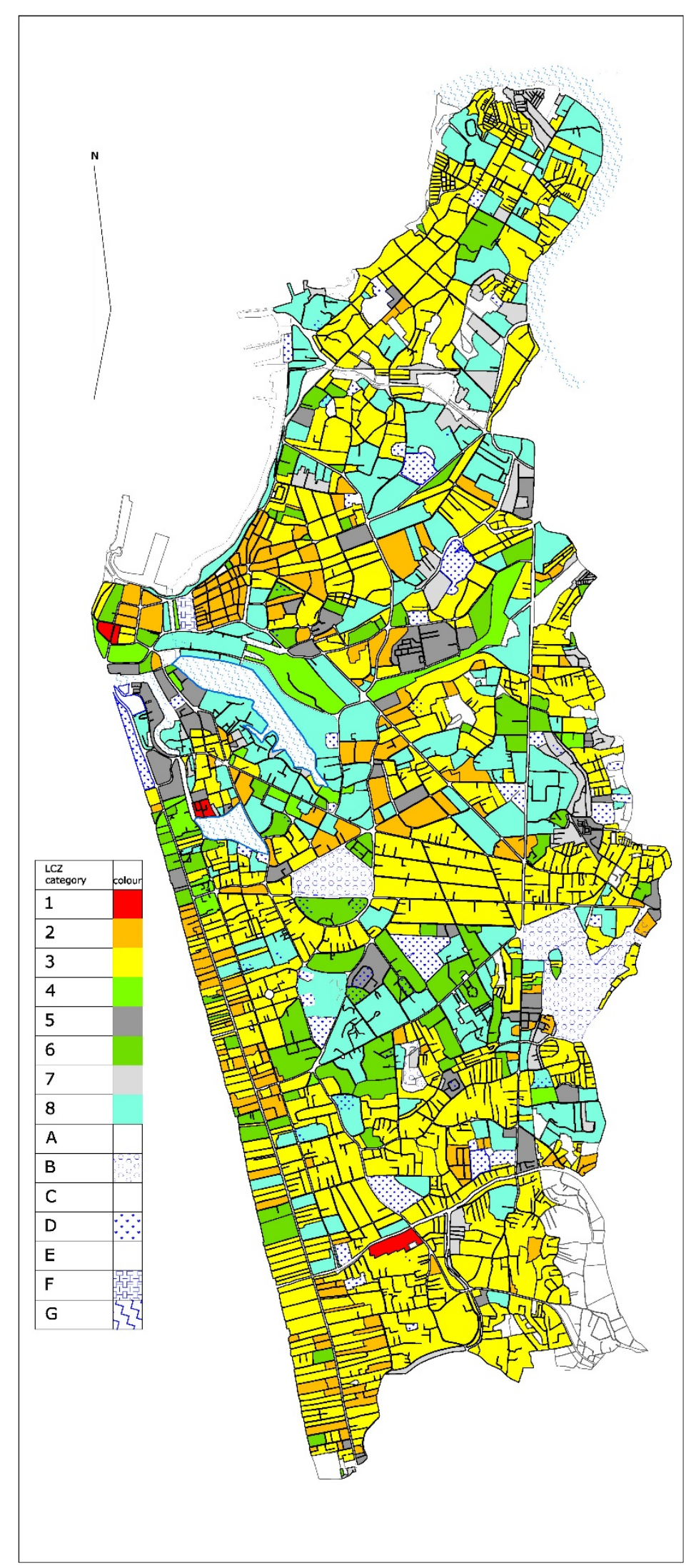

Figure 3: Initial LCZ classification of Colombo 


\subsection{Projected local warming}

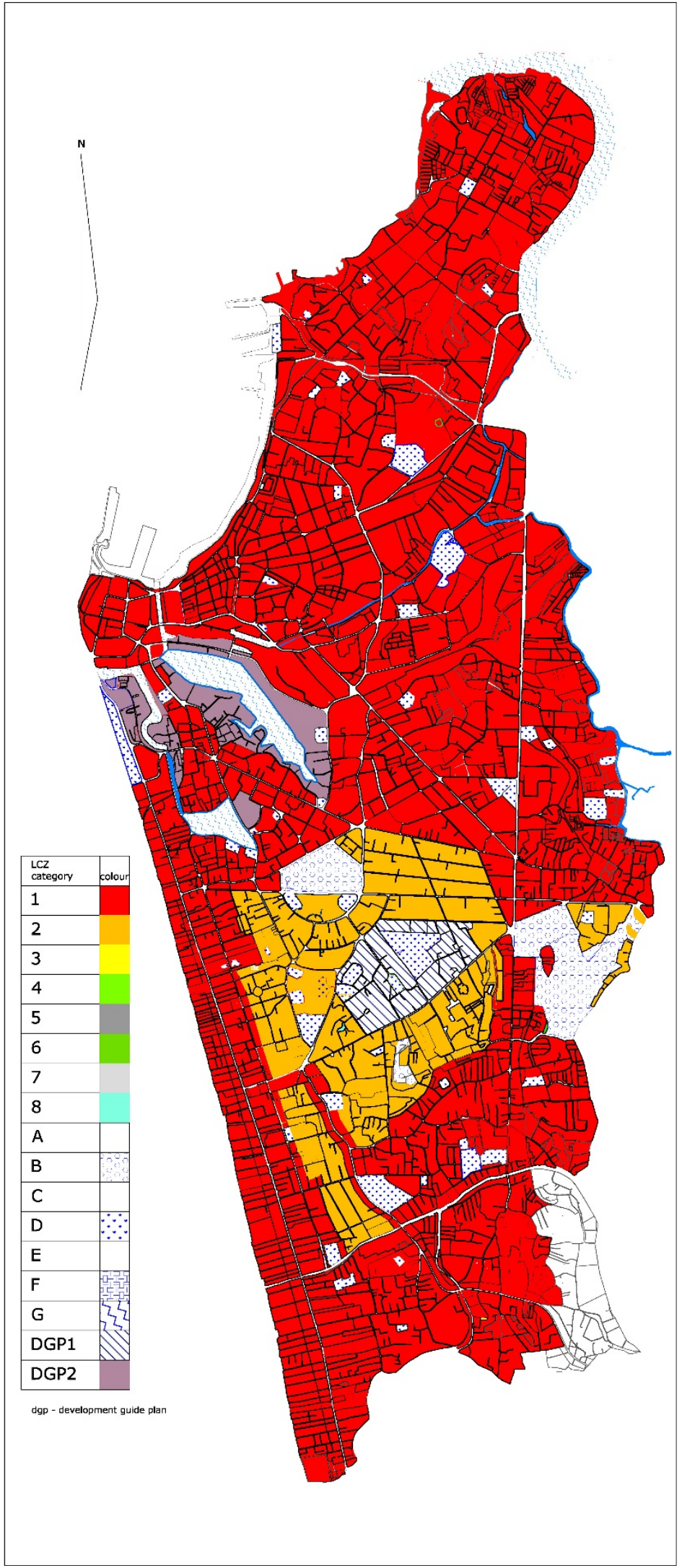

Figure 4: Likely LCZ classification of Colombo in 2020 
Based on Table 1 and Figure 4 it is possible to estimate the likely urban heat island effect in the rapidly changing areas of the city. Table 3 shows a set of likely local warming in the 'built up' LCZ classes (LCZ 1-8) when these are subjected to more intense urban development. It is clear that all land use intensifications lead to local warming but significant differences are likely. The greatest intensity difference of $4.09^{\circ} \mathrm{C}$ is seen when LCZ7 is transformed in to LCZ1. This is happening at very high rate in Colombo, where underserved communities are now being housed in high-rise developments. A socially accepted strategy in the attempt to re-house the underserved settlements is to adopt high density walk-up housing. Table 3 shows that although such a change (LCZ7 to LCZ3) will increase the UHI intensity by $2.88^{\circ} \mathrm{C}$ this seems to be the least harmful change of LCZ7.

Table 3: Projected temperature differences above existing conditions

Source: Perera, 2016

\begin{tabular}{cll|c|c|c|c|c|c|c}
\hline Existing LCZ & \multicolumn{1}{c}{ Projected LCZ } & \multicolumn{1}{l}{} \\
\hline Zone Number & Zone Title & $\mathbf{1}$ & $\mathbf{2}$ & $\mathbf{3}$ & $\mathbf{4}$ & $\mathbf{5}$ & $\mathbf{6}$ & $\mathbf{7}$ & $\mathbf{8}$ \\
\hline 1 & compact high-rise & & & & & & & & \\
2 & compact mid-rise & 0.44 & & & 0.39 & & & & \\
3 & compact low-rise & 1.21 & 0.77 & & 1.16 & & & & \\
4 & open high-rise & 0.05 & & & & & & & \\
5 & open mid-rise & 0.69 & 0.25 & & & & & & \\
6 & open low-rise & 2.53 & 2.09 & 1.32 & 2.48 & 1.84 & & & -0.77 \\
7 & lightweight low-rise & 4.09 & 3.65 & 2.88 & 4.04 & 3.4 & 1.56 & & 0.79 \\
8 & large low-rise & 3.3 & 2.86 & 2.09 & 3.25 & 2.61 & 0.77 & & \\
\hline
\end{tabular}

Another transformation that is currently underway is the change of warehouse areas (LCZ8) into high density development (LCZ1 or LCZ4). This will create further local warming of $3.3^{\circ} \mathrm{C}$ and $3.25^{\circ} \mathrm{C}$ respectively. However, other transformations towards a more compact urban form (such as LCZs 2, 3 and also LCZ5 to either LCZ1 or LCZ2) seem to be the least harmful from a local warming perspective. A further benevolent transformation is LCZ6 changing into LCZ 8 (a reduction of $0.77^{\circ} \mathrm{C}$ ). This is currently seen in Colombo, where residential areas are being transformed into mainly educational institutions.

Figure 4 highlights the danger of fully implementing the Urban Development Authority Projected Zoning Plan for 2020; the planning zones will encourage development that is very similar to each other, both in terms of land use and morphology. Only the "Special Primary Residential Zone" (http://colombo.mc.gov.lk/downloads/ccdp-2008.pdf) (LCZ 2 in the middle of Figure 4) differs in this regard. The zone definition imposes maximum building height of ground plus four floors. Thus, LCZ categorisation of the city becomes limited to only two (built series) LCZs - LCZ1 and LCZ2. A significant consequence is that although the built surface fraction for LCZ1 will be limited to a maximum of $50 \%$, the local warming impact will be considerable (see Table 3 ).

\subsection{Difficulties in applying LCZ classification}

Given that the LCZ approach was originally intended for the siting of urban climate monitoring stations, there are issues in its application to a planning process. The primary issue was with respect to the selection of scale - and therefore the boundary - of the area to be classified. The present approach used the urban blocks as the source area. Yet, block shape, scale and orientation; consideration of the major vehicular arteries, waterways, natural areas and interstitial spaces in general were hard to fit in. The impact of adjacent blocks; surface / ground cover variations and the existence of trees within block boundaries were also problematic and needed to be addressed. 
The larger the area, the more extensive is the mixing of the urban fabric. While the classification simplifies such an area as one predominant LCZ there is a danger that such a large area may not express a uniform climate characteristic, even with sub-classification. For example, an area classified as LCZ5 with sub classification of LCZ4 $\left(\mathrm{LCZ5}_{4}\right)$ does not highlight the natural cover (that maybe LCZB instead of LCZD) that is expected in the pattern. Similarly, too small a area may generate a detailed LCZ classification pattern that is too detailed for planning purposes. Furthermore, the source area size and shape - vary between studies using LCZ method to classify cities. Thus, the reporting and comparison of results may not be accurate. Yet, for individual studies this may not be a problem if the definition of block boundaries / scale is decided upon to fit a specific purpose.

LCZ datasets are developed from generalised knowledge of built forms and land cover types that are universally recognized, not from specialized knowledge of local topography and climatology in individual cities (Stewart and Oke, 2012). Further, in cities like Colombo - where the mixing of the urban fabric is a key characteristic of the city - data ranges are not easy to interpret. The datasets define the primary LCZs only; they do not include value ranges for the sub-classified patterns.

It is in the interpretation of the value ranges associated with the LCZ system to the context of a city that creates the most queries. Particularly in establishing zone specific density and building regulations (Perera, 2015). Zone specific density and building regulations are important to ensure climate sensitive development - at both neighbourhood and city scale - encompassing the aspects of UHI mitigation, outdoor thermal comfort and indoor energy use. The distinct morphology needs of an urban block and / or a city precinct would create variations within blocks, between adjacent blocks or precincts, leading to difficulties in establishing generalised guidelines. This aspect is further discussed in the planning implications Section (5).

The approach to classifying Colombo encompassed local expertise and data on existing and projected planning zones. The boundaries of the selected urban blocks were generated with these factors in mind. Therefore, the general pattern of the LCZ map for the city generally corresponds to its physical structure (compare Figure 3 vs Figure 1). Thus, local knowledge is vital in the LCZ classification procedure - especially when the area in question encompasses a distinctly heterogeneous urban fabric.

\subsection{Simplified LCZ classification process}

\subsubsection{Sub-classification}

A significant number of the LCZs needed to be sub-classified to derive a better representation of local conditions in this high density tropical city. Table 4 shows typical sub-classification patterns for Colombo, Sri Lanka.

Table 4: LCZ and sub-classification patterns for Colombo

Source: Perera, 2016

\begin{tabular}{|c|c|c|c|c|c|c|c|c|c|c|c|c|c|c|}
\hline \multicolumn{2}{|c|}{ LOCAL CLIMATE ZONE } & \multicolumn{13}{|c|}{ Sub-Classification Category } \\
\hline $\begin{array}{l}\text { Zone } \\
\text { Number }\end{array}$ & Zone Title & 1 & 2 & 3 & 4 & 5 & 6 & 7 & 8 & A & B C & $C \quad D$ & $E$ & $F \quad G$ \\
\hline 1 & compact high-rise & $x$ & & & & & & & & & & & & \\
\hline 2 & compact mid-rise & & $x$ & $x$ & $x$ & & & $x$ & & & & & & \\
\hline 3 & compact low-rise & & $x$ & $x$ & $x$ & $x$ & $x$ & $x$ & & & & & & \\
\hline 4 & open high-rise & & $x$ & $x$ & $x$ & & & & & & & $x$ & & \\
\hline 5 & open mid-rise & & & $x$ & $x$ & $\mathrm{x}$ & & & & & $x$ & $x$ & $x$ & $x$ \\
\hline 6 & open low-rise & & & $x$ & & $x$ & $x$ & $x$ & & $x$ & $x$ & $x$ & & $x$ \\
\hline
\end{tabular}




\begin{tabular}{|c|c|c|c|c|c|c|c|c|c|c|c|c|}
\hline 7 & lightweight low-rise & & $x$ & & & $x$ & & & & & & \\
\hline 8 & large low-rise & $x$ & $x$ & $x$ & $x$ & $x$ & $x$ & $x$ & $x$ & $x$ & $x$ & \\
\hline A & dense trees & & & & & & & & & & & \\
\hline B & scattered trees & & & & & & & $x$ & & & & \\
\hline C & bush, scrub & & & & & & & & & & & \\
\hline D & low plants & & & & & & & & $x$ & & & \\
\hline $\mathbf{E}$ & bare rock or paved & & & & & & & & & $x$ & & \\
\hline $\mathbf{F}$ & bare soil or sand & & & & & & & & & & $x$ & \\
\hline G & water & & & & & & & & & & & $x$ \\
\hline
\end{tabular}

The sub-classification of LCZ types where the packing of roughness elements are defined as 'compact' (example LCZs 1 to 3 ) sees a sub-classification with LCZs of mainly the 'built series' (e.g. $\mathrm{LCZ3}_{7}, \mathrm{LCZ2}_{4}$ ), while the 'open' LCZ series (LCZs 4, 5, 6 and 8) is sub-classified with LCZs of the 'land cover series' (Example LCZ8 ${ }_{B}, L_{C Z}$ ). This is most evident in LCZ8, where the nature of the open ground is significant. LCZ3 with sub-classification LCZ7 is noteworthy, where these areas would have been previously categorised as 'Lightweight Low-rise' or 'slum' areas in the city, has now developed with more permanent materials. The development has not changed its plot structure; thus maintain a high aspect ratio (see Figure 5 for typical examples of these sub classification from Colombo).

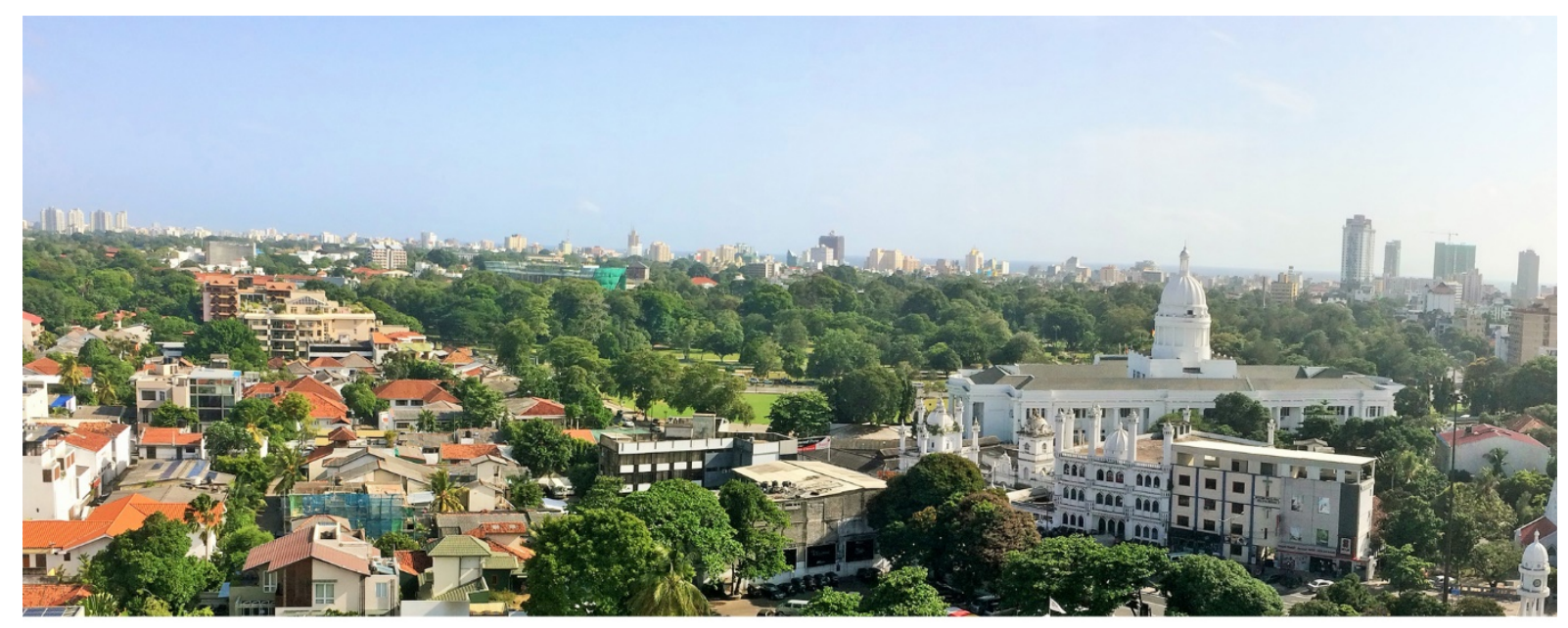

LCZ2 sub categorised with LCZ3 on left and LCZ8 with LCZD on right

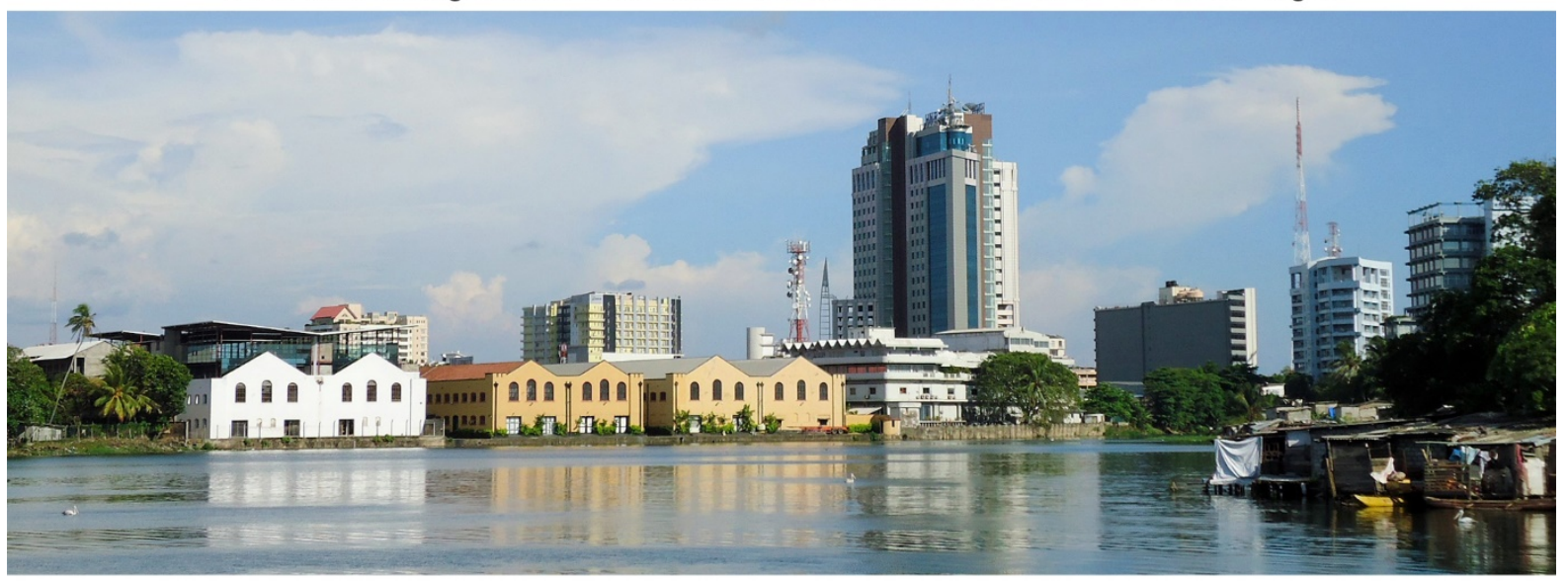

LCZ8 sub categorised with LCZ2

Figure 5: Some examples of significant LCZ sub-classes in Colombo 


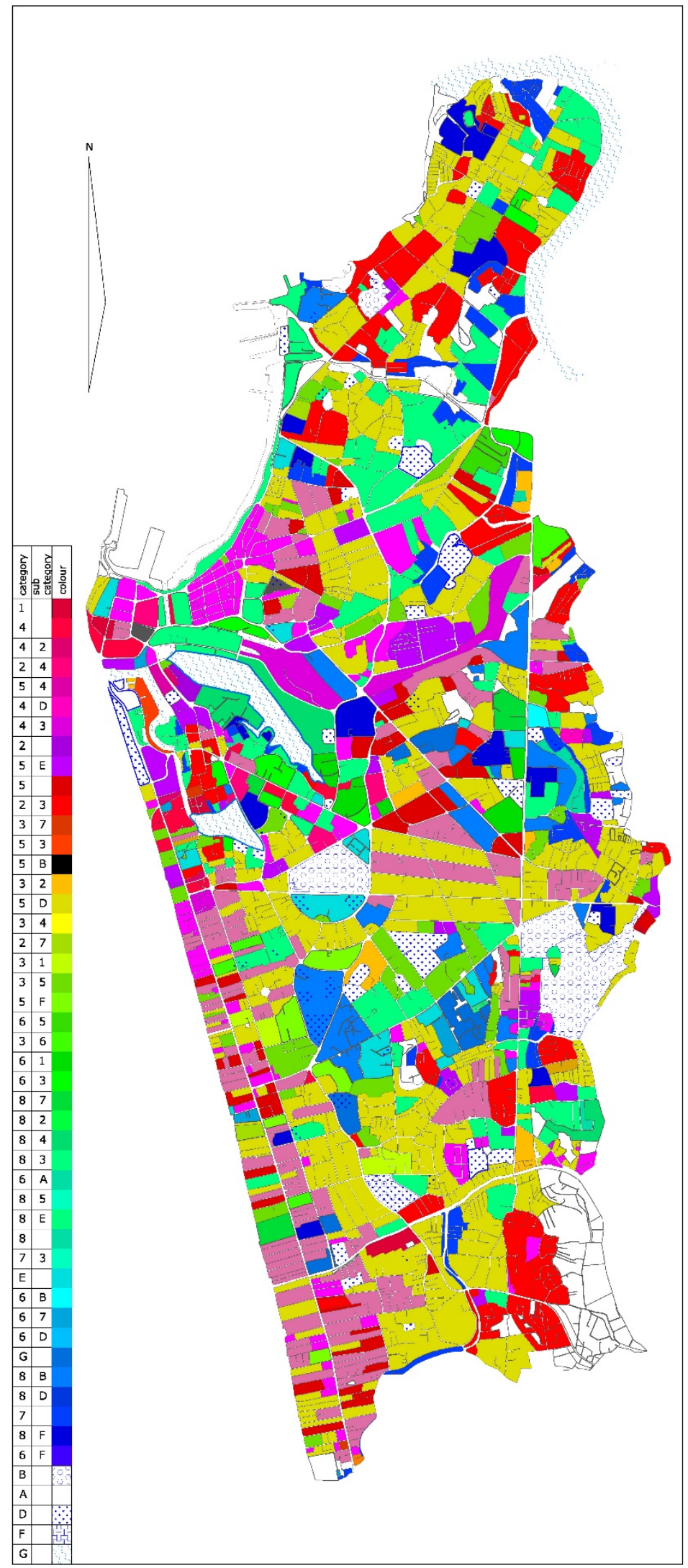

Figure 6: Initial LCZ sub-classification of Colombo

The sub-classified LCZ map of Colombo yielded 46 LCZ combinations, including the primary LCZs (Figure 6). Given that the LCZ system is expected to simplify the urban land use/land cover into 
climatically significant classes, this is too many, and leads to unnecessary fragmentation as seen in Figure 6 . Thus, the next phase was to simplify the sub-classification yet retain all essential information that impinge on local climate. The rationale for simplification is that sub-classification categories focus on building heights and ignore differences in the packing characteristics. For example, a low-rise infusion into a LCZ class could be combined, irrespective of the packing characteristics (such as compact [LCZ3], open set [LCZ6]) or the construction type (such as LCZ7). Table 5 lists the simplified classification used and their nomenclature.

Table 5: Simplification of sub-classification patterns for Colombo

\begin{tabular}{|c|c|c|c|}
\hline \multicolumn{4}{|c|}{ LOCAL CLIMATE ZONE } \\
\hline Zone Number & Zone Title & Sub-Classification simplification rationale & nomenclature adopted \\
\hline 1 & compact high-rise & no sub-classification & 1 \\
\hline 2 & compact mid-rise & $\begin{array}{l}\text { high- rise }(4) \\
\text { low-rise (combine } 3,7)\end{array}$ & $\begin{array}{l}2_{4} \\
2_{3,7}\end{array}$ \\
\hline 3 & compact low-rise & $\begin{array}{l}\text { high-rise (4) } \\
\text { mid-rise (combine } 2,5 \text { ) } \\
\text { low-rise (combine } 3,6,7 \text { ) }\end{array}$ & $\begin{array}{l}3_{4} \\
3_{2,5} \\
3\end{array}$ \\
\hline 4 & open high-rise & $\begin{array}{l}\text { mid-rise (2) } \\
\text { low-rise (3) } \\
\text { plant cover (combine D. due to open } \\
\text { categories consider plant cover) }\end{array}$ & $\begin{array}{l}4_{2} \\
4_{3,8} \\
4\end{array}$ \\
\hline 5 & open mid-rise & $\begin{array}{l}\text { high-rise (4) } \\
\text { low-rise (3) } \\
\text { plant cover (combine A to D) } \\
\text { Hard landscape (combine E,F) }\end{array}$ & $\begin{array}{l}5_{4} \\
5_{3,7} \\
5_{A, B, C, D} \\
5_{E, F}\end{array}$ \\
\hline 6 & open low-rise & $\begin{array}{l}\text { low-rise (combine } 3,7) \\
\text { mid-rise }(5) \\
\text { plant cover (combine A to D) } \\
\text { Hard landscape (combine E,F) }\end{array}$ & $\begin{array}{l}6_{3,7} \\
6_{5} \\
6_{A, B, C, D} \\
6_{E, F}\end{array}$ \\
\hline 7 & $\begin{array}{l}\text { lightweight low- } \\
\text { rise }\end{array}$ & no sub-classification & 7 \\
\hline 8 & large low-rise & $\begin{array}{l}\text { high-rise (4) } \\
\text { mid-rise (combine } 2,5) \\
\text { low-rise (combine } 3,6,7 \text { ) } \\
\text { plant cover (combine A to D) } \\
\text { Hard landscape (combine E,F) }\end{array}$ & $\begin{array}{l}8_{4} \\
8_{2,5} \\
8_{3,6,7} \\
8_{A, B, C, D} \\
8_{E, F}\end{array}$ \\
\hline A & dense trees & no sub-classification & \\
\hline B & scattered trees & no sub-classification & \\
\hline C & bush, scrub & no sub-classification & \\
\hline D & low plants & no sub-classification & \\
\hline $\mathbf{E}$ & bare rock or paved & no sub-classification & \\
\hline $\mathbf{F}$ & bare soil or sand & no sub-classification & \\
\hline G & water & no sub-classification & \\
\hline
\end{tabular}

This exercise reduced the number of sub-classified LCZs to $31-16$ primary and 15 sub-classes. This simplified mapping allows a clearer interpretation (Figure 7). For example, in LCZ8, it is clear to distinguish functional areas like schools ( $L C Z 8_{A, B, C, D}$ with generally natural cover), with those of a more commercial nature (LCZ8 ${ }_{E, F}$ with paved cover for parking). The location of the latter category indicates key commercial nodes in the city. 


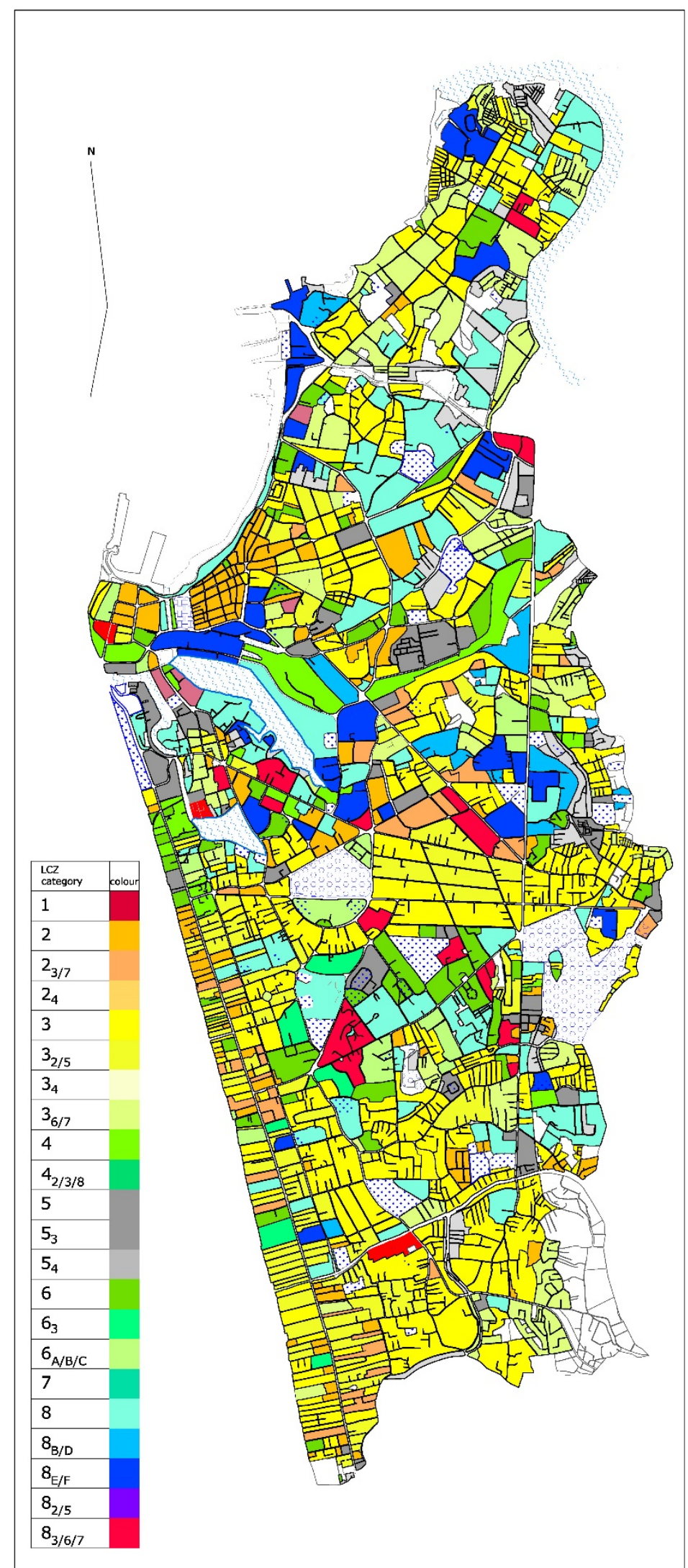

Figure 7: Simplified LCZ sub classification of Colombo 


\section{Implications - Integrating an LCZ-based approach with the planning system}

The LCZ classification system in its incorporation of urban morphology (both geometric and surface cover), thermal and anthropogenic properties into a mapping protocol has significant advantages for climate sensitive and context specific urban planning. Whereas the current planning approach in Colombo is largely landuse-based (with some consideration of urban activities) an LCZ-based approach allows for the easy identification of critically stressed areas. For example, as can be seen in Table 1 and Figure 3, areas identified as LCZ1 could be expected to have the highest UHI intensity. It can also highlight areas that need to be preserved to avoid an increase in local level warming. Examples could include zones such as LCZ2, LCZ3, LCZ8, where further development - usually to LCZ1 - should be avoided.

A further advantage of an LCZ-based zoning approach is the degree of flexibility offered to the design and monitoring stages of urban development. The specification of 'value ranges' for geometric, surface cover, thermal and radiative properties and anthropogenic heat (as given in Table 2 of Stewart and Oke, 2012) and sub-classification as shown here, will generate sufficient heterogeneity and design flexibility in the urban fabric. Furthermore, an LCZ-based approach is also able to incorporate social and economic considerations that drive the current landuse-based planning approach. For example, value ranges for anthropogenic heat factors in economic activity; if the 'value ranges' are sufficiently wide there is room for an equitable development that offers a variety of pathways to achieve the end goal of sustainable urban development.

\subsection{Data and process needs for the simplified system}

Before an LCZ-based approach to urban planning is undertaken, a set of data and process needs must be met. Such needs for a simplified LCZ classification system are dependent on the distinct stages of the process: Planning and policy stage; Design and approval stage; Monitoring and compliance stage.

Planning and policy stage - The primary need is to understand the existing urban fabric in terms of its key local climate-influencing parameters. Freely available base maps consisting of building footprints, streets and natural features, are vital. While these are increasingly available freely (e.g. Geo-wiki) the availability of local expertise with specific knowledge of climatic goals appropriate for the context is also needed to correctly categorise urban land cover/land use. Familiarity with the planning goals and likely future urban form and development needs will also be vital in correctly classifying the existing fabric.

Design and approval stage - Transparency and certainty are the key needs of this stage to ensure timely decision making and appropriate resource utilisation. Thus, explicit threshold values for 'acceptable' ranges of key geometric and surface cover properties is a vital need at this stage. Together with this, publicly available detailed maps projecting the future changes envisaged at local level and a comprehensive rating matrix of urban parameters to aid decision making (e.g. CASBEE, 2013) are also needed.

Monitoring and compliance stage - A continually updated / maintained digital database of city characteristics, together with a monitoring network for microclimate impacts of envisioned planning intervention can be utilised. It also needs to include socio-economic data feedback, thus establish possibilities for fine tuning of the approach.

A LCZ-based approach does not negate the need for building level regulations, which form the backbone of built environment control in many cities. What it does is to specify value ranges for building level controls in terms of plot size, street width, building surface fraction, impervious 
surface fraction, building height and thermal properties of buildings at the scale of an urban block rather than a large swathe of a city. This provides further flexibility at the scale of individual buildings to achieve the same end goal. Herein lie the importance of urban block based source area classification that was utilised in the mapping process.

\section{Conclusions}

The advantage of an LCZ-based zoning approach is that 'classes are local in scale, climatic in nature, and zonal in its representation' (Stewart and Oke 2012). The system provides a protocol for rapid mapping and remains comparable across similar urban contexts. In this paper, we have demonstrated the benefits of such a system in a data-scarce context in the developing world. However some caveats are in order.

1. Like all classification systems, LCZ approach is reductionist in nature that is not able to capture all of the nuances of urban growth everywhere. Some degree of local customisation is needed. We have suggested that this could be achieved via a context specific sub-classification system, but this needs additional work.

2. The flexibility offered by an LCZ-based approach at the urban block level could also be a double edged sword in that its ability to shape future growth in a large swathe of a city is diminished. A compromise may need to be found between the urban block level and the planning zone level.

3. We have used the value ranges specified by Stewart and Oke (2012) for geometric, surface cover and thermal properties, but questions remain with regard to their universal application. While the ranges are driven by their influence on local climate, a planning system based on such ranges need to be cognizant of the socio, political realities and stakeholder acceptability of these. .

As acknowledged by Stewart and Oke $(2012,2014)$ LCZ datasets are developed from generalised knowledge of built forms and land cover types that are universally recognised, not from specialised knowledge of local topography and climatology in individual cities. It is now time that contextspecific knowledge from several tropical cities are applied to both the classification and the creation of sub-classes so as to enhance its usefulness to this data-poor but rapidly changing region.

\section{References}

Alexander P, Mills, G. 2014. Local Climate Classification and Dublin's Urban Heat Island, Atmosphere, 5, 755774

Bechtel B, Alexander PJ, Böhner J, Ching J, Conrad O, Feddema J, Mills G, See L, Stewart I. 2015. Mapping Local Climate Zones for a Worldwide Database of the Form and Function of Cities, ISPRS International Journal of Geo-Information, 4, 199-219

Brousse O, Martilli A, Foley M, Mills G, Bechtel B. 2016. WUDAPT, an efficient land use producing data tool for mesoscale models? Integration of urban LCZ in WRF over Madrid, Urban Climate, 17, 116-134

Ching JKS. 2013. A perspective on urban canopy layer modelling for weather, climate and air quality applications. Urban Climate, 3, 13-39

Urban Development Authority, City of Colombo Development Plan (Amendment) - 2008 the Law No. 41 of 1978 (Gazette of Democratic Socialist Republic of Sri Lanka Extraordinary No 1535/4 of 06th February, 2008) (Available at http://colombo.mc.gov.lk/downloads/ccdp-2008.pdf - last accessed 10.11.2016)

CASBEE - Comprehensive Assessment System for Built Environment Efficiency. (Available at http://www.ibec.or.jp/CASBEE/english/index.htm last accessed 10.11. 2016) 
Dept. of Census and Statistics, 2012. Population of Sri Lanka by District - Census of Population and Housing 2011 Preliminary Report, Colombo: Dept. of Census and Population, ISBN: 978-955-577-781-0

Emmanuel R, 2005. Thermal comfort implications of urbanization in a warm-humid city: The Colombo Metropolitan Region (CMR), Sri Lanka, Building and Environment, 40, 1591-1601

Emmanuel R, Loconsole A. 2015. Green infrastructure for overheating adaptation in Glasgow, Landscape and Urban Planning, 138, 71-86

Emmanuel R, Johansson E. 2006. Influence of urban morphology and sea breeze on hot humid microclimate: the case of Colombo, Sri Lanka. Climate Research, 30, 3, 189-200

Emmanuel R, Rosenlund H, Johansson E. 2007. Urban shading - a design option for the tropics? A study in Colombo, Sri Lanka. International Journal of Climatology, 27, 14, 1995-2004

Georgescu M, Morefield PE, Bierwagen BG, Weaver CP. 2014. Urban adaptation can roll back warming of emerging megapolitan regions. In PNAS, 111, 8, 2909-2914

Grimmond CSB, Roth M, Oke TR, Au YC, Best M, Betts R, Carmichael G, Cleugh H, Dabberdt W, Emmanuel R, Freitas E, Fortuniak K, Hanna S, Klein P, Kalkstein LS, Liu CH, Nickson A, Pearlmutter D, Sailor D, Voogt J. 2010. Climate and More Sustainable Cities: Climate Information for Improved Planning and Management of Cities (Producers/Capabilities Perspective). Procedia Environmental Sciences, 1, 247274

Japan International Coorporation Agency (2014). Urban Transport System Development Project, Colombo. Available at http://www.transport.gov.Ik/web/images/stories/F-CoMTrans_Main S.pdf

Johansson E, Emmanuel R, 2006. The influence of urban design on the outdoor thermal comfort in the hot, humid city of Colombo, Sri Lanka, Int'l. J. Biometeorology, 51, 2, 119-133

Leconte F, Bouyer J, Claverie R, Pétrissans M. 2015. Using Local Climate Zone scheme for UHI assessment: Evaluation of the method using mobile measurements, Building and Environment, 83, 39-49

Middel A, Häb K, Brazel AJ, Martin CA, Guhathakurta S. 2014. Impact of urban form and design on midafternoon microclimate in Phoenix Local Climate Zones, Landscape and Urban Planning, 122, 16-28

Mills G. 2007. Cities as agents of global change. International Journal of Climatology, 27, 14, 1849-1857

Mills G, Cleugh H, Emmanuel R, Endlicher W, Erell E, McGranahan G, Ng E. 2010. Climate Information for Improved Planning and Management of Mega Cities (Needs Perspective), Procedia Environmental Sciences, 1, 228-246

Müller N, Kuttler W, Barlag A.-B. 2013. Counteracting urban climate change: adaptation measures and their effect on thermal comfort, Theoretical and Applied Climatology, 115, 1-2, 243-257

Ng E. 2016. Urban air ventilation in high-density cities in the tropics. In, Emmanuel R. (ed.), 2016. Urban Climate Challenges in the Tropics: Rethinking Planning and Design Opportunities, London: Imperial College Press

Ng E, Ren C. (eds.). 2015. The Urban Climatic Map: A Methodology for Sustainable Urban Planning. Routledge: London

Oke TR. 2006. Towards better communication in urban climate. Theoretical and Applied Climatology, 84, 179189

Peng LLH, Jim CY. 2013. Green-roof effects on neighbourhood microclimate and human thermal sensation, Energies, 6, 2, 598-618

Perera NGR. 2015. Climate-Sensitive Urban Public Space: A Sustainable Approach to Urban Heat Island Mitigation in Colombo, Sri Lanka, PhD Thesis, University of Moratuwa, Sri Lanka

Perera NGR. 2016. Chapter 7: Urban climate mapping in the tropics in Urban Climate Challenges in the Tropics: Rethinking Planning and Design. . In, Emmanuel R. (ed.), Urban Climate Challenges in the Tropics: Rethinking Planning and Design Opportunities, London: Imperial College Press, 205-254

Puliafito SE, Bochaca FR, Allende DG, Fernandez R. 2013. Green areas and microscale thermal comfort in arid environments: A case study in Mendoza, Argentina. Atmospheric and Climate Sciences, 3, 3, 372-384 
Ren C, Ng E, Katzschner L.2011. Urban climatic map studies: A review. International Journal of Climatology, 31, 2213-2233

Roth M. 2007. Review of urban climate research in (sub) tropical regions. International Journal of Climatology, 27, 14, 1859-1873

See L, Bechtel B, Ching JKS, Feddema JJ, Foley M, Fritz S, Masson V, Mills G, Perger C, Stewart ID. 2015. Developing a community-based worldwide urban morphology and materials database (WUDAPT) using remote sensing and crowdsourcing for improved urban climate modelling, 2015 Joint Urban Remote Sensing Event (JURSE), Lausanne, 2015, pp. 1-4. doi: 10.1109/JURSE.2015.7120501

Siu LW, Hart M. 2013. Quantifying urban heat island intensity in Hong Kong SAR, China, Environmental Monitoring and Assessment, 185, 5, 4383-4398

Stewart ID, Oke TR, Krayenhoff ES. 2014. Evaluation of the 'local climate zone' scheme using temperature observations and model simulations, Int. J. Climatology, 34, 1062-1080

Stewart ID, Oke TR. 2012. 'Local Climate Zones' for urban temperature studies, Bulletin of the American Meteorological Society, 93, 1879-1900

Thomas G, Sherin AP, Ansar S, Zachariah EJ. 2014. Analysis of Urban Heat Island in Kochi, India, Using a Modified Local Climate Zone Classification. Procedia Environmental Sciences, 21, 3-13

Unger J, Lelovics E, Gál T. 2014. Local Climate Zone mapping using GIS methods in Szeged, Hungarian Geographical Bulletin, 63, 1, 29-41

Urban Development Authority (UDA), 2008. City of Colombo Development Plan (Amendment) - 2008. Available at http://colombo.mc.gov.lk/downloads/ccdp-2008.pdf, last accessed 10.11.2016

Villadiego K, Velay-dabat MA. 2014. Outdoor thermal comfort in a hot and humid climate of Colombia: A field study in Barranquilla, Building and Environment, 75, 142-152 
